\title{
Caracterização hidrológica e ambiental de uma pequena bacia do baixo Rio Tapajós (AM)
}

Bacia hidrográfica é considerada como uma área naturalmente delimitada pela topografia e drenada por um sistema conectado de cursos de água. Devido às atividades antrópicas, essas bacias são alteradas e descaracterizadas, sofrendo profundas mudanças em suas estruturas aquática e terrestre. Para caracterizar uma pequena bacia hidrográfica pertencente ao sistema de drenagem do rio Tapajós, foram adotados cinco pontos de amostragem ao longo da Bacia do lgarapé São Braz. Foram coletados dados morfométricos da bacia hidrográfica, de abertura do dossel e sobre a integridade do habitat; os parâmetros físico-químicos da água e estruturais do canal, foram coletados ao longo de três períodos do ciclo sazonal. A bacia hidrográfica do São Braz apresenta área de aproximadamente $234.738 \mathrm{~km}{ }^{2}$ e formato circular. As características hidrológicas e limnológicas apresentam variação espacial e temporal, sem um padrão consistente ao longo do tempo. A estocasticidade observada pode ser decorrente de diferenças na intensidade e origem dos processos promotores de degradação ambiental nas nascentes hidrográficas estudadas. O índice de integridade do habitat foi capaz de determinar o estado de degradação dos igarapés estudados na bacia hidrográfica do São Braz, onde apenas duas nascentes foram determinadas como íntegras. Os resultados obtidos neste estudo reforçam a importância no planejamento de ações para prevenir a degradação nos ambientes considerados íntegros e para minimizar e reverter fontes de impacto que promovam a degradação da Bacia do São Braz.

Palavras-chave: Gestão de bacias hidrográficas; Qualidade da água; Mata ciliar.

\section{Hydrological and environmental characterization of a small basin of the lower Tapajós River (AM)}

\begin{abstract}
Watershed is considered as an area naturally bounded by topography and drained by a connected system of watercourses. Due to anthropogenic activities, these basins are altered and uncharacterized, undergoing profound changes in their aquatic and terrestrial structures. To characterize a small watershed belonging to the Tapajós River drainage system, five sampling points were adopted along the Igarapé São Braz Basin. Morphometric data of the watershed, canopy opening and habitat integrity were collected; the physical-chemical water and structural parameters of the canal were collected over three periods of the seasonal cycle. The São Braz watershed has an area of approximately $234,738 \mathrm{~km}^{2}$ and a circular shape. Hydrological and limnological characteristics show spatial and temporal variation, without a consistent pattern over time. The stochasticity observed may be due to differences in the intensity and origin of the environmental degradation promoting processes in the studied hydrographic springs. The habitat integrity index was able to determine the state of degradation of the studied streams in the São Braz watershed, where only two springs were determined as intact. The results obtained in this study reinforce the importance of planning actions to prevent degradation in environments considered to be healthy and to minimize and reverse sources of impact that promote the degradation of the São Braz Basin.
\end{abstract}

Keywords: River basin management; Water quality; Riparian forest.

Topic: Ciências Florestais

Reviewed anonymously in the process of blind peer
Received: 01/07/2018

Approved: $12 / 07 / 2018$ lara Bruna Brito da Silva

Universidade Federal do Oeste do Pará, Brasil

http://lattes.cnpq.br/5276752049549557

yarabruna18@gmail.com

Ana Paula dos Anjos Pinto

Universidade Federal do Oeste do Pará, Brasil

http://lattes.cnpq.br/2872006033892493

pauladosanjos83@gmail.com

\section{Amanda Frederico Mortati (iD)}

Universidade Federal do Oeste do Pará, Brasil

http://lattes.cnpq.br/0557586915080502

http://orcid.org/0000-0001-9150-990X

amortati@gmail.com
Leidiane Leão de Oliveira

Universidade Federal do Oeste do Pará, Brasil

http://lattes.cnpq.br/5016148560650320

leidianeoli@gmail.com
Referencing this:

SILVA, I. B. B.; PINTO, A. P. A.; MORTATI, A. F.; OLIVEIRA, L. L. Caracterização hidrológica e ambiental de uma pequena bacia do baixo Rio Tapajós (AM). Revista Ibero Americana de Ciências Ambientais, v.9, n.6, p.14-27, 2018. DOI: http://doi.org/10.6008/CBPC2179-6858.2018.006.0002 


\section{INTRODUÇÃO}

A água é um bem importante para gerar e promover a existência de qualquer ser vivo. Sua utilidade é fundamental, tanto para o equilíbrio ecológico, quanto para o desenvolvimento humano. No entanto, esse bem indispensável à vida e em abundância na região amazônica, apresenta grandes desafios quanto à administração (CHIOQUETA, 2011). A questão problemática na região amazônica está relacionada com a qualidade dos recursos hídricos. 'As redes de abastecimento de água, de saneamento básico, ainda são muito frágeis aqui na região'. Mesmo com os picos de enchentes, gerando abundância de recursos hídricos, percebe-se que o saneamento básico tem comprometido a qualidade dos recursos hídricos. "E a crise que nós podemos ter aqui é na verdade, mais de qualidade do que de quantidade de água" (ABISABER, 2017).

De acordo com Silveira (2001), a bacia hidrográfica é considerada um sistema físico, com sua área definida topograficamente, drenada por um curso de água ou um sistema conectado de cursos de água, onde o seu elemento de entrada é o volume de água precipitada. A saída do volume de água é escoada pela vazão através de uma única saída. A Bacia poderá conter sub-bacias secundárias fechadas, nas quais as águas superficiais terão sumidouros ou lagos que não estão ligados à rede hidrográfica do curso de água principal (GARCEZ, 1988). Tais bacias são afetadas, como todos os outros ecossistemas aquáticos e terrestres, pelas inúmeras atividades humanas (TUNDISI et al., 2008). Nessas pequenas bacias hidrográficas, as consequências das mudanças do uso da terra na Amazônia são mais agudas.

Segundo Neill et al. (2006), grande parte dos ecossistemas aquáticos amazônicos é constituída por complexas redes de corpos d'água, formadas, em sua maioria, por pequenos riachos, ligados à terra por fluxo de água, via escoamento superficial e subsuperficial. Os estudos desses pequenos canais são importantes, pois permitem a quantificação de todos os caminhos de fluxo dos corpos d'águas que estão ligados a transformações biogeoquímicas e transporte de materiais dissolvidos e particulados, importante para interface terrestre-aquática. O volume de água no igarapé não varia de forma gradual e previsível como nos rios, mas estão relacionados com a ocorrência de eventos mais curtos e mais frequentes (ESPÍRITO-SANTO et al., 2009).

Estudos de monitoramento hidrológico e ambiental em pequenas bacias hidrográficas na Amazônia ainda são raros ou de curta duração (NEIL et al., 2006; BLEICH et al., 2014). Menor ainda é a informação sistematizada e quantitativa a respeito da representatividade dos pequenos cursos de água que formam estas bacias hidrográficas. A importância relativa de riachos de primeira e de segunda ordem (conforme o método Horton-Strahler) é imensa, podendo somar $84 \%$ do comprimento total do rio Cuieiras, cuja bacia de drenagem abrange $3300 \mathrm{~km}^{2}$ na Amazônia central (MCCLAIN et al., 2001) e 74\% da bacia do Rio Ji-Paraná ao longo de $75000 \mathrm{~km}^{2}$, na Amazônia ocidental (BALLESTER et al., 2003).

Incentivar e promover a pesquisa em pequenas bacias hidrográficas é crucial na Amazônia. Os pequenos cursos de água e suas respectivas bacias de captação são afetados pelo processo comum de degradação nas áreas de terra firme, como a abertura de estradas e o processo de ocupação humana associado às atividades agropecuárias (FEARNSIDE, 2003), além de grandes áreas de garimpo (SANTOS, 2002), e mais recentemente os empreendimentos hidroelétricos (FEARNSIDE et al., 2012). 
Segundo Tucci (2008), devido à ocupação de forma acelerada, há uma consequente modificação da cobertura vegetal da bacia, pela retirada da sua proteção natural, dessa forma, o solo tende a ficar desprotegido, reduzindo sua capacidade de infiltração e facilitando o escoamento superficial. Além de promover um notável aumento da erosão durante o período chuvoso, intensificando a produção de sedimentos, que em grande parte ficam retidos no fundo de rios e lagos.

Nesse sentido, a presente pesquisa tem como objetivo a caracterização hidrológica e ambiental de uma pequena bacia hidrográfica amazônica, por meio da análise de parâmetros estruturais da bacia como morfologia e tamanho, dos canais como vazão e características físico-químicas da água, e da integridade ambiental da interface aquático-terrestre (igarapé e sua vegetação ripária), promovendo avanços para o conhecimento científico e para tomada de decisões no âmbito da gestão territorial e da conservação da natureza.

\section{MATERIAIS E MÉTODOS}

\section{Área de estudo}

A bacia hidrográfica do São Braz pertence à bacia de drenagem do Rio Tapajós e está situada no município de Santarém, localizada na região Amazônica, próximo à confluência dos Rios Amazonas e Tapajós. Foram definidos cinco pontos amostrais, que podem ser visualizados na figura 1, constituídos cada um por um tributário da bacia, localmente denominados igarapés: Vila Nova, Cucurunã, Irurama, São Braz (ao longo das comunidades do Eixo forte, cujo acesso se dá pela Rodovia Estadual Everaldo Martins - PA-457) e Juá (com acesso pela Avenida Engenheiro Fernando Guilhon), com seus respectivos códigos e coordenadas apresentados na tabela 1.

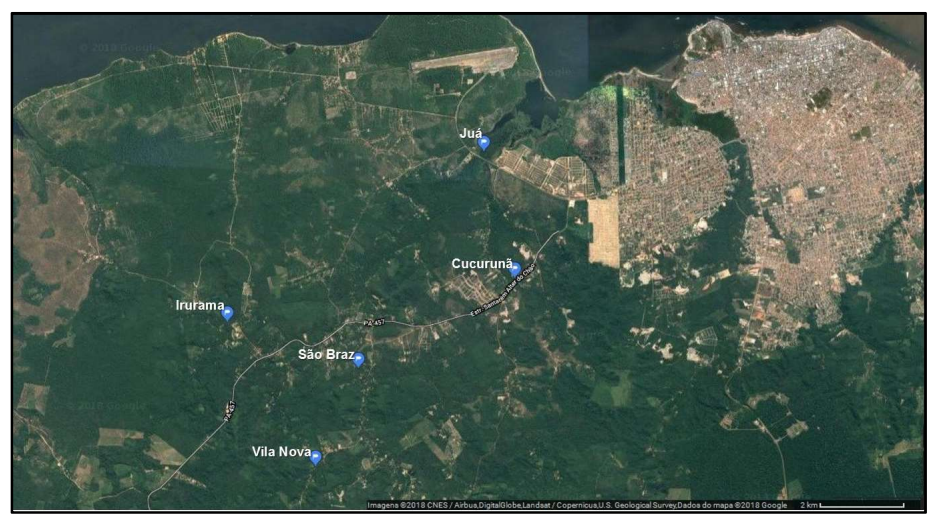

Figura 1: Mapa de localização dos 5 igarapés amostrados no município de Santarém (PA).

Tabela 1: Descrição dos pontos de amostragem da pequena bacia do São Braz, Santarém (PA).

\begin{tabular}{|l|l|l|l|}
\hline IGARAPÉ & CÓDIGO & LATITUDE & LONGITUDE \\
\hline Vila Nova & SB01 & $2.514^{\circ}$ & $54.82492^{\circ}$ \\
\hline São Braz & SB02 & $2.492194^{\circ}$ & $54.81561^{\circ}$ \\
\hline Irurama & SB03 & $2.482028^{\circ}$ & $54.84394^{\circ}$ \\
\hline Cucurunã & SB04 & $2.472194^{\circ}$ & $54.78186^{\circ}$ \\
\hline Juá & SB05 & $2.444056^{\circ}$ & $54.78861^{\circ}$ \\
\hline
\end{tabular}

O clima predominante da região é considerado quente e úmido, com valores médios anuais de precipitação de $1920 \mathrm{~mm}$, enquanto a precipitação média mensal varia de 170 a $300 \mathrm{~mm}$ no período chamado 
de 'inverno' que ocorre de dezembro a maio a precipitação média mensal. Em contraposição nos meses de junho novembro correspondente ao período mais seco os valores médios são inferiores a $60 \mathrm{~mm}$. A temperatura média anual varia de $25^{\circ}$ a $28^{\circ} \mathrm{C}$ e umidade média relativa do ar de $86 \%$.

\section{Amostragem}

A extração da rede de drenagem, os mapas aqui apresentados, bem como a coleta de dados para caracterização do tamanho e da forma da bacia (área, perímetro, comprimento, coeficiente de compacidade, fator de forma e índice de circularidade) foram executados no software livre QUANTUM GIS, utilizando como referencial topográfico imagens do radar SRTM (Shuttle Radar Topography Mission), 1 arc sec para dados de altitude. As inspeções na imagem foram realizadas de forma supervisionada para corrigir manualmente a delimitação de área da bacia, a partir da identificação dos divisores de água, e para a extração dos dados de tamanho e forma.

\section{Parâmetros físico-químicos e estruturais}

Para a coleta deste conjunto de dados, foram adotadas as instruções estabelecidas no protocolo padronizado para coleta de parâmetros ambientais em igarapés de pequeno porte, e para cada um dos cinco pontos preestabelecidos na bacia foram selecionados trechos de $50 \mathrm{~m}$, fragmentados em quatro transectos transversais (MENDONÇA et al., 2005). Para a caracterização da qualidade da água foram medidos os seguintes parâmetros físico-químicos: $\mathrm{pH}$, condutividade, oxigênio dissolvido, temperatura e turbidez, aferidos com a utilização do PHmetro, Condutivímetro $(\mu \mathrm{S} / \mathrm{cm})$, Oxímetro $(\mathrm{mg} / \mathrm{L}$ e \%) e Turbidímetro (NTU) digitais. Para a caracterização do canal dos igarapés, foram medidos largura média do canal, profundidade média e máxima, velocidade da corrente e vazão média, abertura média do dossel. Tais parâmetros foram aferidos com a utilização de trenas, câmera digital e medidor de ultrassom Doppler.

Conforme Mendonça et al. (2005), a largura média do canal foi calculada a partir da média de 4 medidas equidistantes ao longo do trecho determinado. A profundidade média do canal e profundidade máxima média foram calculadas a partir de 9 sondagens equidistantes em quatro transectos transversais ao longo do trecho. A velocidade da corrente foi determinada pela média entre quatro ponto dispostos no centro do canal, medida no meio da coluna d'água, utilizando um fluxímetro ou medindo-se o tempo de deslocamento de um objeto flutuante por uma distância conhecida.

A vazão média $(\mathrm{m} 3 / \mathrm{s})$ foi obtida relacionando-se velocidade média, largura e profundidade, pela fórmula: $Q=A . V m$, onde $Q=$ vazão; $V m$ = velocidade média da corrente; e $A$ = área transeccional média na secção transversal do curso de água. A área transeccional foi calculada a partir da média da área de 4 transectos em cada trecho estudado, pela fórmula: $A t=\Sigma$ niAn, na qual $A t=$ área do transecto dada pela somatória de $[(Z 1+Z 2) / 2] . I+[(Z 2+Z 3) / 2] . I+\ldots[(Z n+Z n+1) / 2] . I$, onde $Z n=$ profundidade medida em cada segmento; e I = largura de cada segmento.

A abertura média do dossel (\%) foi determinada a partir de análises de imagens fotográficas da vegetação. Foram obtidas fotografias digitais do dossel em quatro pontos equidistantes ao longo do trecho, 
padronizando-se a abertura e a velocidade do obturador da câmera (f. 5.6 e 1/60, respectivamente), bem como o horário da aquisição das imagens (entre 8h e 11h). Foram utilizados editores digitais de imagens, sendo as fotografias revertidas para imagens monocromáticas (preto e branco) e através da proporção entre as áreas com vegetação (em preto nas imagens) e as áreas de luz incidente (em branco) foi determinada a abertura do dossel média para cada igarapé através do cálculo '(NPB.100)/NPT', onde NPB é o número de pixels brancos da foto e NPT é o número de pixels totais da foto.

\section{Características morfométricas da bacia}

Para determinar o tamanho da Bacia do Igarapé São Braz, a área, o perímetro e o comprimento total da bacia foram obtidos através da delimitação da hidrografia e da área de drenagem da bacia, com o auxílio da imagem de radar SRTM, para dados de elevação do terreno e uso do programa QGIS. Para determinação do grau de circularidade da bacia do igarapé São Braz e consequentemente dimensionar sua susceptibilidade a picos de grande vazão, foram utilizados estimadores.

Os avaliadores foram: Coeficiente de Compacidade $(\mathrm{Kc})$ : determinado pela fórmula $\mathrm{Kc}=0,28 \frac{\mathrm{P}}{\sqrt{\mathrm{A}}}$, onde $\mathrm{P}=$ perímetro da bacia e $\mathrm{A}=$ área da bacia (CARVALHO et al., 2007); Fator de Forma (F): corresponde à razão entre a largura média da bacia e seu comprimento axial (CARVALHO et al., 2007), onde Kf $=\frac{A}{L^{2}}$; e Índice de Circularidade (Ic): avalia o grau de alongamento da bacia, tende para unidade à medida que a bacia se aproxima da forma circular (CARVALHO et al., 2007). Pode ser calculado com a fórmula: Ic $=\frac{12,57 * \mathrm{~A}}{\mathrm{p}^{2}}$, onde $\mathrm{A}$ é a área da bacia e $\mathrm{P}$ seu perímetro.

\section{Integridade ambiental}

A integridade ambiental dos pontos monitorados na bacia em estudo foi determinada por um protocolo de avaliação rápida da integridade do habitat (BLEICH et al., 2014). Este protocolo é composto por uma tabela de pontuação que atribui valores para diversas características locais do canal, como estado de conservação das margens do canal e dos mecanismos de retenção do leito. Além disso, ele também considera aspectos da vegetação e paisagem ripárias, como a proporção de espécies nativas e a extensão e continuidade da vegetação. Valores próximos a 1 indicam alta integridade do habitat e valores menores que 0,85 já indicam algum tipo de alteração (NESSIMIAN et al., 2008).

\section{DISCUSSÃO TEÓRICA}

\section{Caracterização da bacia}

Através da imagem de radar SRTM, para dados de elevação do terreno, a área da bacia do São Braz foi delimitada a partir do ponto de deflúvio do igarapé na localidade do ponto Juá, em direção aos divisores de água da bacia. Na imagem, os pixels mais claros na escala de cinza representam áreas com maior elevação, e os mais escuros representam áreas mais baixas, onde se concentram os igarapés (figura 2). As características de tamanho e forma da bacia foram expressas em termos quantitativos (tabela 2). Tais 
características podem demostrar as relações entre os fatores de forma e o comportamento hidrológico da bacia (CARVALHO et al., 2007).

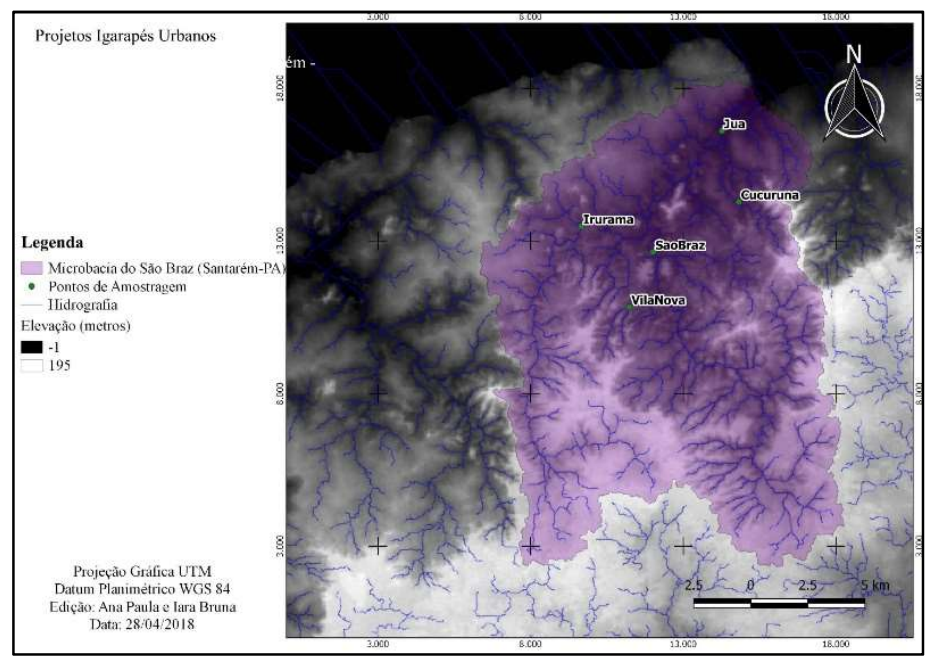

Figura 2: Mapa de delimitação da área da Bacia do Igarapé São Braz, com os pontos de amostragem do Igarapé Vila Nova (SB-01), São Braz (SB-02), Irurama (SB-03), Cucurunã (SB-04), Juá (SB-05), gerado no software livre QGIS.

Tabela 2: Características Físicas da bacia do São Braz, Santarém (PA).

\begin{tabular}{|l|c|}
\hline Características Físicas & Resultados \\
\hline Área & $234,738 \mathrm{~km}^{2}$ \\
\hline Perímetro & $66,661 \mathrm{~km}^{2}$ \\
\hline Comprimento & $21,3 \mathrm{~km}^{2}$ \\
\hline Largura máxima & $11,02 \mathrm{~km}$ \\
\hline Fator Forma (Kf) & 0,52 \\
\hline Índice de Circularidade (IC) & 0,66 \\
\hline Coeficiente de Compacidade (KC) & 1,22 \\
\hline
\end{tabular}

Segundo Carvalho et al. (2007), a bacia possuirá tendência a circularidade quando o resultado do coeficiente de compacidade se aproximar da unidade (a unidade indica uma bacia perfeitamente circular) e em contraposição, o resultado do Fator de forma for maior. Já o índice de circularidade, de acordo com Schumm (1956), indicará tendência mais circular quando o valor obtido for maior que 0,51, o que favorece os processos de inundação. Em vista disso os dados da tabela indicam que a bacia possui tendência a circularidade, portanto, há maiores possibilidades de chuvas intensas ocorrerem em toda sua extensão.

\section{Parâmetros fisico-químicos}

De acordo com os dados obtidos durante os períodos chuvosos (2016/2017) e seco (2015), o ponto amostrado que apresentou maior variação referente ao potencial hidrogeniônico foi o SB-05, entre 4,97 a 6,93, com mediana em torno de 5,0. Enquanto o ponto com menor variação ocorreu no SB-03, valores entre 4,87 a 4,97, com mediana em torno de 4,9. SB-01 e SB-02 obtiveram medianas 4,5 e 4,7, respectivamente, e o SB-04 apresentou maior mediana entre os pontos, aproximadamente 5,4 (figura 3A).

Com valores entre 4,47 a 6,93, o período chuvoso de 2016 registrou uma maior variação em relação ao período chuvoso de 2017 (4,42 a 5,4). O período seco apresentou variação $(4,76$ a 4,97), mostrou medianas aproximadas a 4,9. Dos cinco pontos analisados SB-02 sempre apresentou valores mais baixos nos dois períodos, enquanto SB-05 os valores mais altos (figura 3B). 

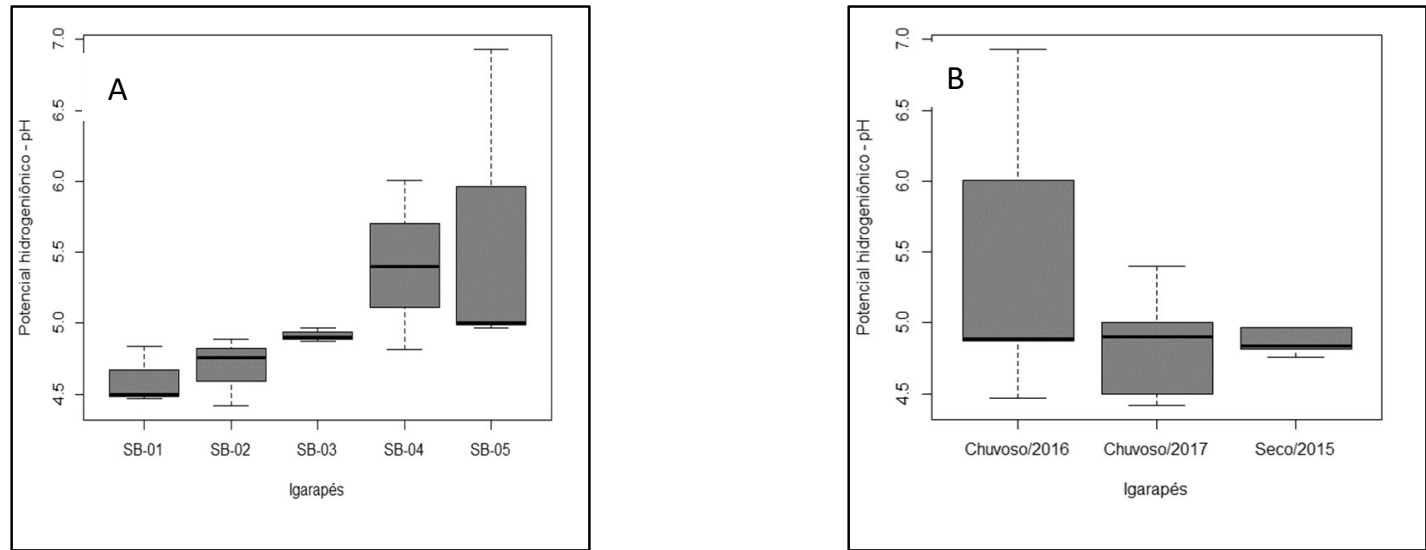

Figura 3: (A) Potencial hidrogeniônico para cada ponto; (B) pH para sazonalidade.

As águas naturais superficiais podem apresentar $\mathrm{pH}$ variando entre 6 a 8,5, sendo esse intervalo mais propício à manutenção da vida aquática, embora haja uma maior concentração representativa de matéria orgânica, onde são resultantes de atividades como a fotossíntese, respiração, intemperismo além dos esgotos domésticos e industriais (LIBÂNIO, 2010). Seguindo esse critério, os pontos SB-04 e SB-05 apresentaram os valores mais aproximados do requisito para haver manutenção da vida no ambiente aquático. Os demais pontos apresentaram dados de $\mathrm{pH}$ abaixo de 5 , considerado com teor mais ácido.

É importante ressaltar que parâmetros de qualidade da água para o desenvolvimento da vida aquática podem variar muito entre as redes hidrográficas, sem muito comumente observadas águas ácidas em igarapés pristinos na Amazônia, em diversas das suas sub-bacias, como a do Rio Negro e do próprio Rio Tapajós. Adicionalmente, os pontos SB-04 e SB-05 não foram detectados como íntegros (ver sessão integridade ambiental aqui nos resultados). Desse modo, para igarapés do baixo rio Tapajós, espera-se encontrar em condições naturais pH mais ácido.

Os pontos que mostraram maiores variações no parâmetro temperatura foram SB-04 e SB-05, e o ponto com menor variação foi o SB-03. Dentre os cinco pontos analisados, o SB-05 destacou-se com maior valor, apresentando temperatura em torno de $28^{\circ} \mathrm{C}$ e o SB-03 com temperatura aproximada a $25,3^{\circ} \mathrm{C}$ - menor valor registrado (figura 4A). Durante o período seco houve grande variação e elevados valores da temperatura, com mediana de $27^{\circ} \mathrm{C}$. O período chuvoso de 2016 apresentou mediana em torno de $26,6^{\circ} \mathrm{C}$, enquanto o período chuvoso de 2017 não apresentou variação, porém mostrou mediana igual a $26^{\circ} \mathrm{C}$ (figura $4 B)$.
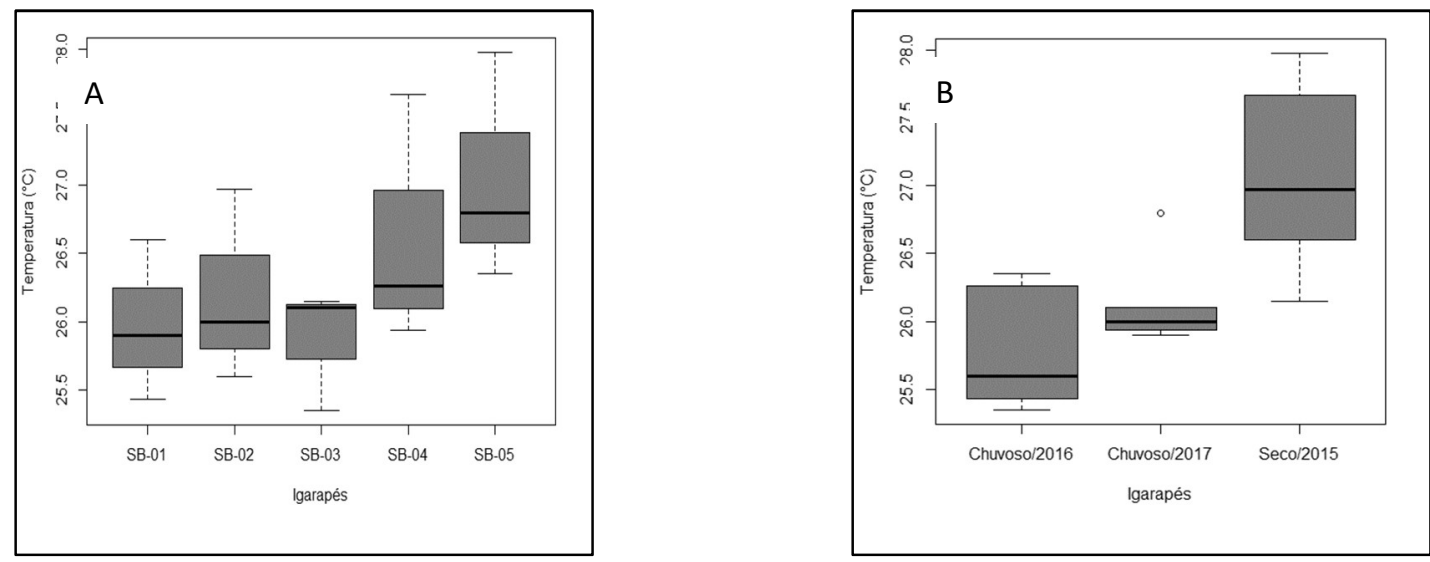

Figura 4: (A) Temperatura para cada ponto; (B) Temperatura para sazonalidade. 
A temperatura é diretamente relacionada a concentração de oxigênio dissolvido no ambiente aquático. Suas alterações são respostas a atividades antrópicas e a naturais como a insolação (quantidade de radiação proveniente do Sol que incide sobre a superfície da coluna d'água) e o clima (LIBÂNIO, 2010).

O registro de temperatura mais baixa se deu no ponto SB-03 onde há preservação da vegetação e dossel fechado sobre o canal do igarapé. A temperatura mais alta registrada foi no SB-05, onde o tamanho do canal e a degradação da mata ciliar impedem o sombreamento da lâmina d’água. Logo, a presença ou ausência da mata ciliar interfere diretamente na temperatura do ambiente aquático (ARCOVA et al., 1999).

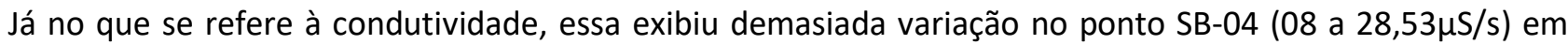
relação aos outros pontos amostrados, visto que, estes apresentaram moderada variação (figura 5A).
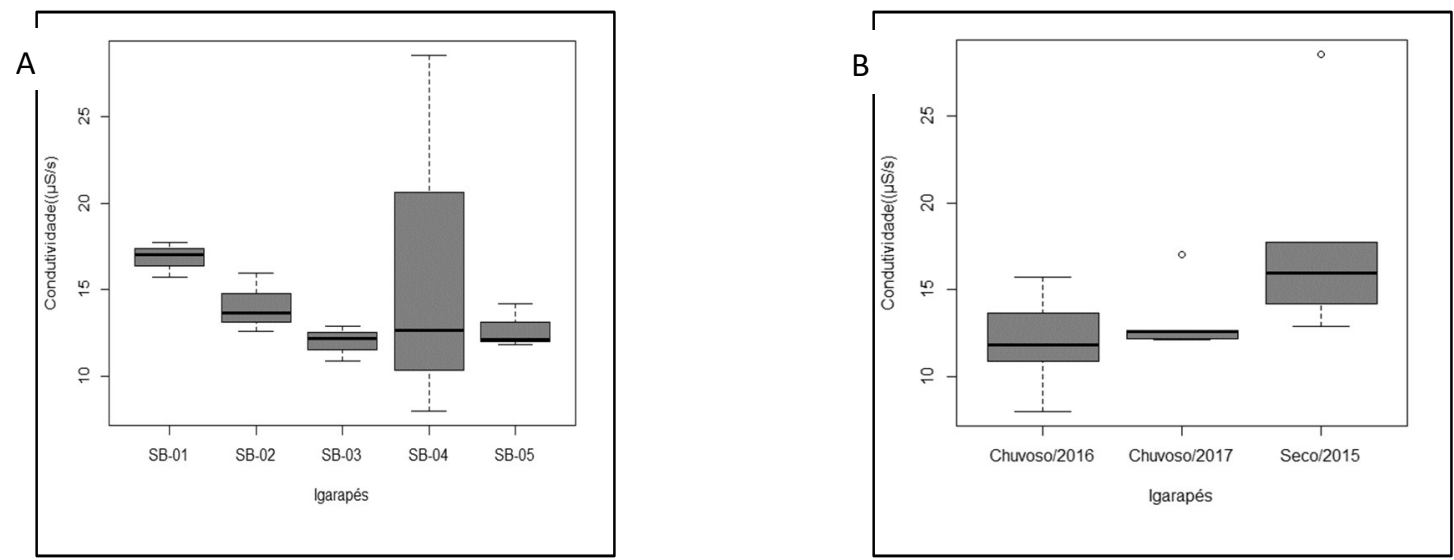

Figura 5: Condutividade para cada ponto; (B) Condutividade para sazonalidade.

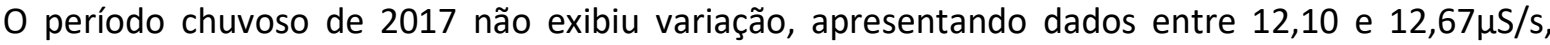

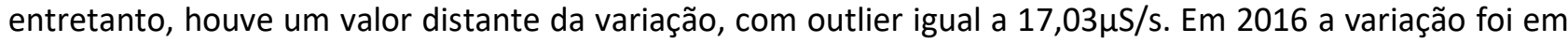
torno de 8,00 e $15,70 \mu \mathrm{S} / \mathrm{s}$. O período seco de 2015 correspondeu a 12,90 a 17,70 $\mathrm{S} / \mathrm{s}$ com dado discrepante

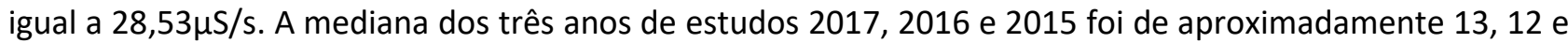
16, respectivamente (figura 5B). Valores elevados de condutividade elétrica podem estar relacionados à degradação ambiental (MASESE et al., 2014), contudo, esta variável parece responder a eventos pontuais e caraterísticas locais que podem comprometer a identificação de um estado de degradação quando utilizada separadamente (BLEICH et al., 2014).

O oxigênio apresentou maior variação no SB-04 (4,22 a 8,25mg/l), ele mostrou o maior valor entre os pontos. A menor variação registrada foi no SB-01 (2,39 a 3,77mg/l), onde esses valores não corresponderam aos teores mínimos de oxigênio necessário para manutenção da vida aquática aeróbio (figura 6A).

O período chuvoso de 2016 mostrou maior variação, com valores entre 2,39 a 8,5mg/l, apresentando o menor e o maior valor registrado dos três anos de coleta. Durante o período seco houve pouca variação, entre 3,77 a 6,11. As medianas apresentadas foram de aproximadamente $5 \mathrm{mg} / \mathrm{I}$ no período chuvoso de 2016 e seco de 2017 e no período chuvoso de 2015 em torno de 6,5mg/l (figura 6B).

De acordo com a resolução CONAMA 357/2005 o oxigênio dissolvido, em qualquer amostra, não deve ser inferior a $6 \mathrm{mg} / \mathrm{L}$, dessa forma, o SB-01(3,14mg/l), SB-03 $(5,53 \mathrm{mg} / \mathrm{l})$ e SB-05 $(4,15 \mathrm{mg} / \mathrm{I})$ são classificados fora do padrão estabelecido. O SB-01 (2,39 a 3,77mg/l) apresentou valores inadequados, pois a 
maioria das espécies de peixes não resistem a concentrações de oxigênio dissolvidos na água inferiores a $4,0 \mathrm{mg} / \mathrm{l}$.
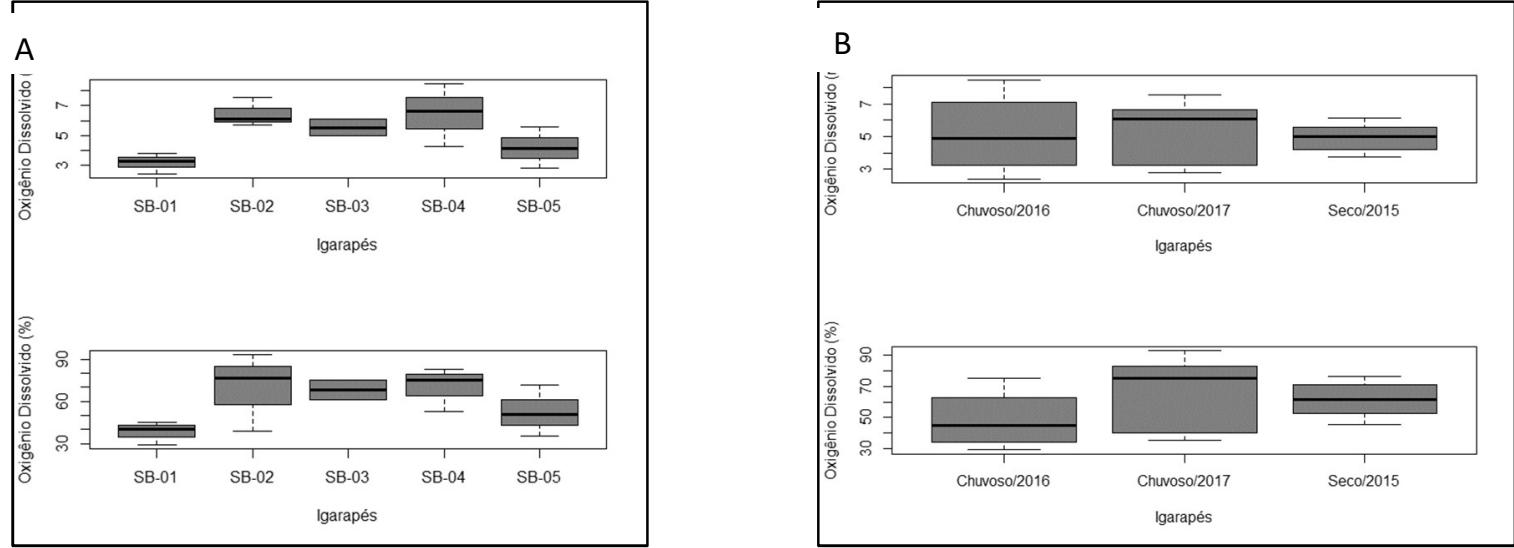

Figura 6: (A) Oxigênio Dissolvido para cada ponto; (B) Oxigênio Dissolvido para sazonalidade.

O SB-04 expressou significativa variação de turbidez (4,78 a 130,33NTU) em contraste ao SB-01 (0,02 a 2,21NTU). A mediana do SB-01, SB-03 e SB-05 mostrou valores abaixo de aproximadamente 10 NTU, dentro dos padrões estabelecidos pelo CONAMA onde a turbidez atinge até 40NTU (figura 7A). A variação sazonal apresentou valores discrepantes nos três anos de estudo, onde o período chuvoso de 2017 apresentou maior variação com outlier igual a 130,33, referente ao SB-04, pois para esse período houve um aumento significativo do transporte de sedimento aos corpos de água, agravando-se ainda mais devido a atividades antrópicas (figura 7B).
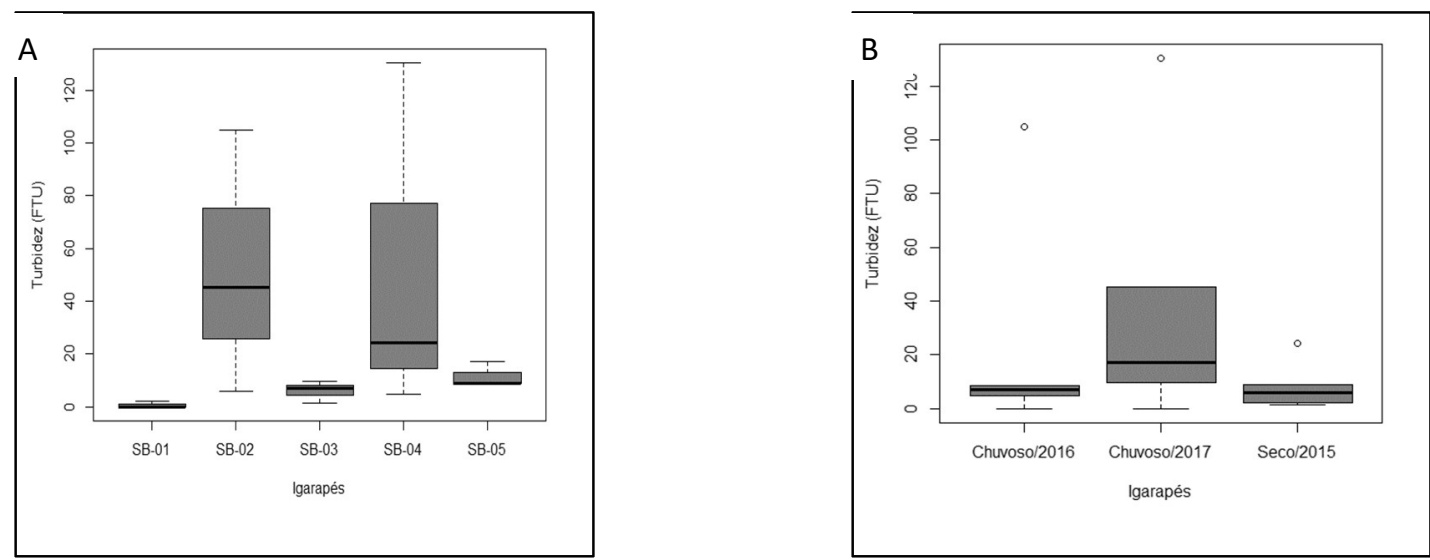

Figura 7: (A) Turbidez para cada ponto; (B) Turbidez para sazonalidade.

SB-02 e SB-04 mostraram valores elevados de até 130,33NTU, ultrapassando os padrões da Resolução, muito embora, as medianas estejam em níveis aproximados do ideal. Segundo Brasil (2014), a turbidez de corpos d'água é particularmente alta em regiões com solo erosivo, onde a precipitação pluviométrica pode carrear partículas. Segundo Libânio (2010), no período de seca observa-se uma significativa redução da turbidez, como mostra o SB-04 com um valor já excedente para o período seco (24,14 NTU). 


\section{Parâmetros estruturais}

Houve variação entre os pontos amostrados, visto que, para o SB-05, houve uma variação maior (5 a 19m), e para o SB-03 uma ínfima variação (3,25 a 3,88m). Das medianas, o SB-05 registrou o maior valor, aproximadamente $12 \mathrm{~m}$, enquanto o SB-02 mostrou mediana igual a $8 \mathrm{~m}$ e o SB-01, SB-03 e SB-04 apresentaram medianas abaixo de $5 \mathrm{~m}$ (figura $8 \mathrm{~A}$ ).
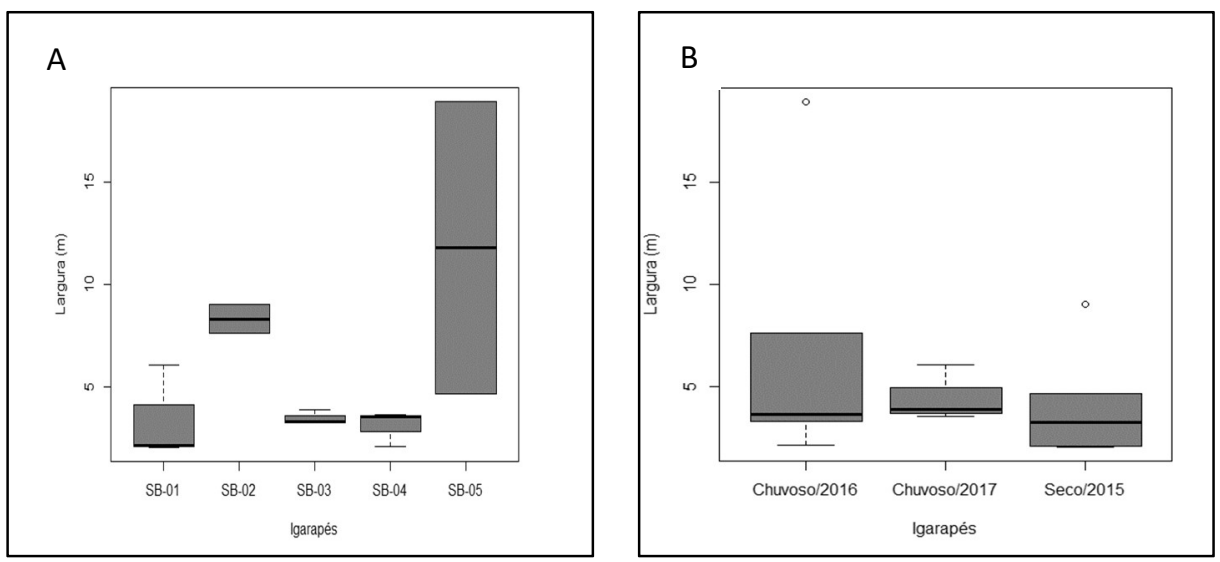

Figura 8: (A) Largura para cada ponto; (B) Largura para sazonalidade.

O período chuvoso de 2017 mostrou menor variação, enquanto o chuvoso de 2016 maior variação, apresentando um outlier igual a 18,90m o período seco de 2015 com outlier igual a 9,02m sendo o SB05. (figura 8B). Igarapés mais próximos de grandes rios sofrem maior influência do pulso de inundação por estarem inseridos dentro da planície de inundação de um canal maior e que alaga anualmente. Além disso, a retirada da vegetação ciliar promove a desestabilização das margens, podendo o mesmo apresentar maior largura no período ou evento de chuva (TUCCI, 2008).

O SB-02 apresentou considerável variação, com mediana em torno de $5 \mathrm{~m}^{3} / \mathrm{s}$, em relação aos outros pontos, cujas medianas não ultrapassaram $1 \mathrm{~m}^{3} / \mathrm{s}$ (figura $9 \mathrm{~A}$ ). O período seco não apresentou variação relevante, mas o período chuvoso de 2016 e 2017 obteve valores de 0,04 a 1,99m³/s com outlier igual a $9,98 \mathrm{~m}^{3} / \mathrm{s}$ no SB-02 em 2016 (figura 9B).
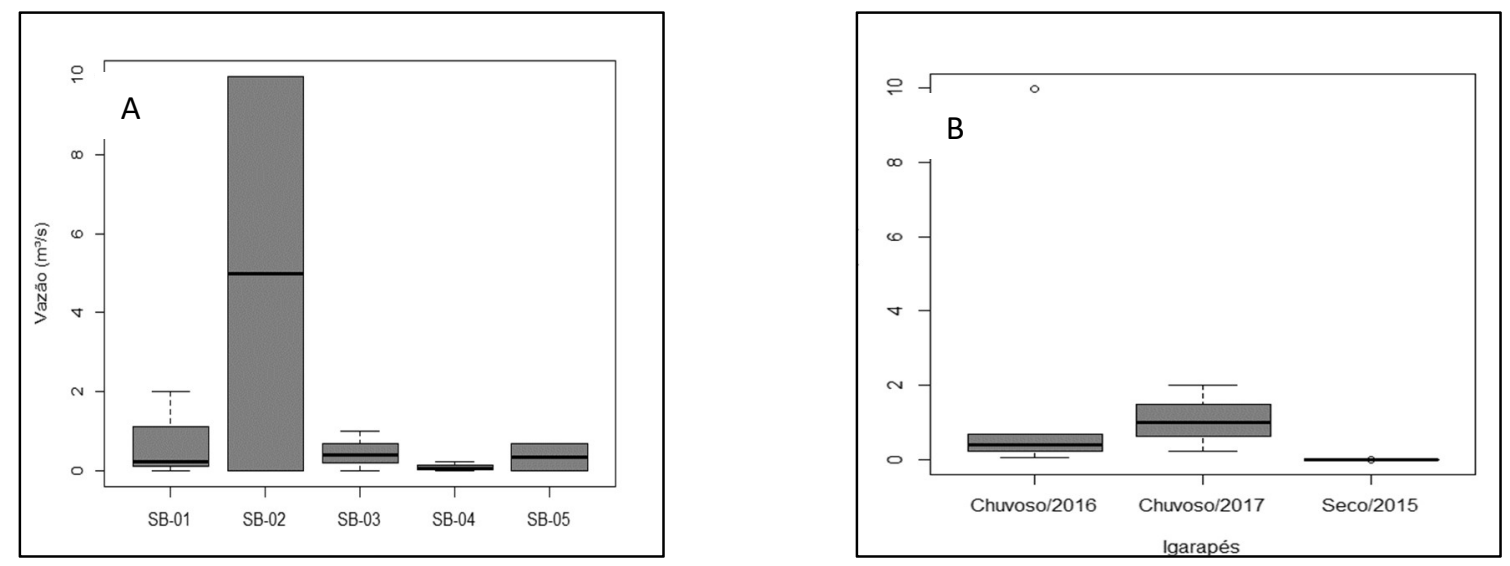

Figura 9: Vazão para cada ponto (A); vazão para sazonalidade (B).

O SB-01 apresentou profundidade média em torno de 0,2m e a máxima obteve variação de 0,34 a 0,85m. O SB-02 apresentou profundidade média em torno de 1,0m e a máxima obteve variação de 1,19 a 
1,74m. No SB-03 a média foi de aproximadamente 0,4m e a máximo variou de 0,64 a 0,88m. O SB-04 mostrou média em torno de 0,19m e máxima variando de 0,23 a 0,38m. O SB-05 mostrou média de 0,25m e máxima de 0,50m (figura 10A). Nos períodos sazonais de estudo não houve variação da profundidade média dos pontos de amostragem, porém destaca-se a profundidade máxima um pouco mais elevada no período chuvoso de 2017 comparado com os outros períodos analisados (figura 10B).
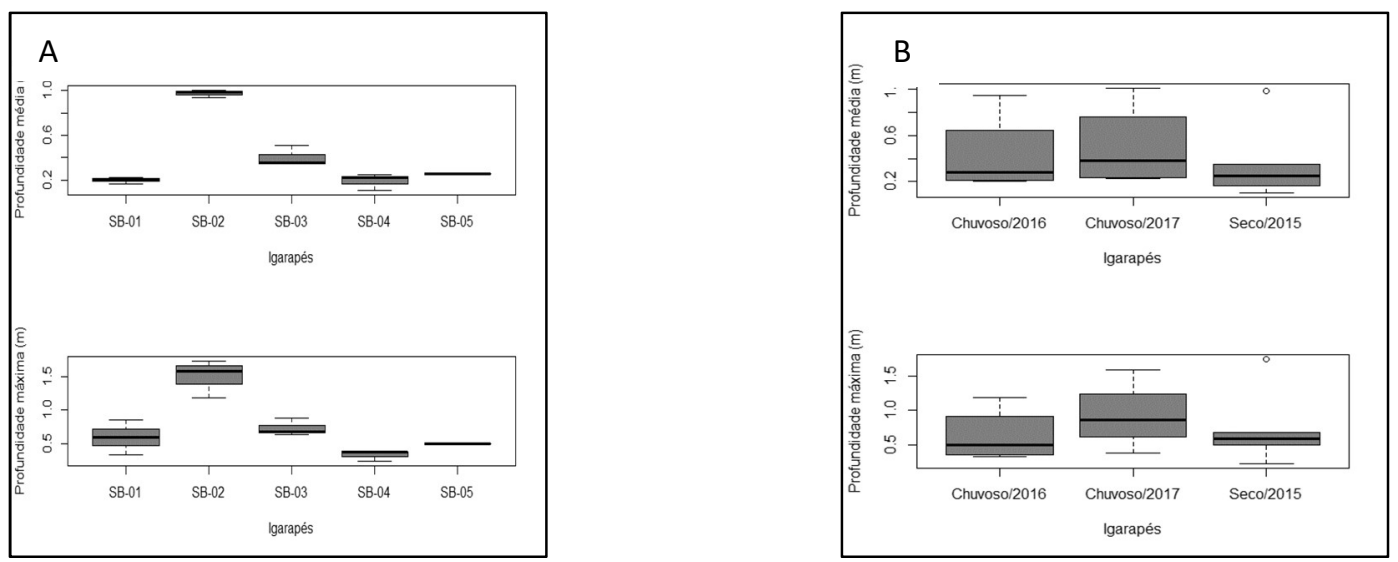

Figura 10: (A) Profundidade máxima e média para cada ponto; (B) Profundidade máxima e média para sazonalidade.

\section{Abertura de dossel}

Os pontos SB-01, SB-02 e SB-04 indicaram medianas aproximadas a 30\%, valor este com significativa diferença em relação ao SB-05, que indicou aproximadamente $80 \%$ de abertura e o SB-03, em torno de $21 \%$. Com relação à variação, os pontos SB-01, SB-03 e SB-05 destacaram-se (figura 11). O SB-05 (80\%) expressou a maior porcentagem de abertura do dossel, dessa forma o ambiente pode ser considerado com a cobertura menor de mata ciliar.

A ausência ou redução da vegetação marginal acarreta diversas consequências para os recursos hídricos, tornando as margens suscetíveis a erosão, processo que resulta no assoreamento do corpo hídrico e o expõe a radiação solar, com consequente a elevação da temperatura (BASTOS et al., 2004). O SB-01, SB02, SB-03 e SB-04 apresentam menores porcentagens de abertura de dossel, devido a maior presença de vegetação no entorno dos pontos de amostragem, indicando a presença de mata ciliar definida e vegetação densa.

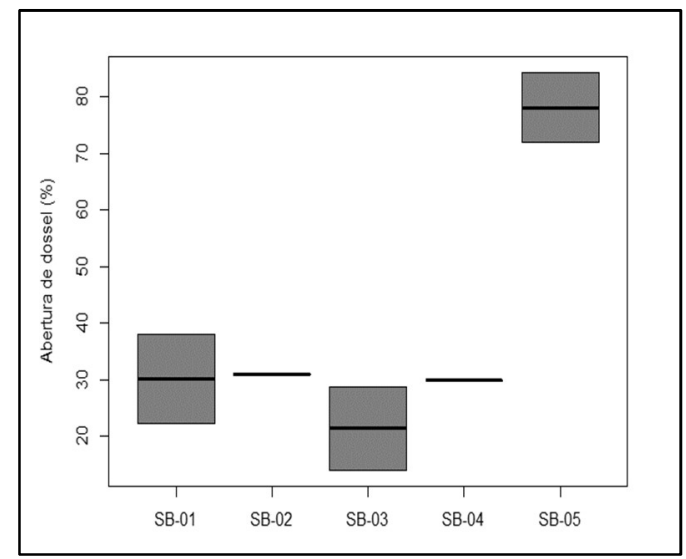

Figura 11: Abertura de dossel para cada ponto. 


\section{Índice de Integridade Habitat (IIH)}

Foram considerados íntegros os pontos SB-02 (85 \%) e SB-03 (92\%), pois apresentaram índices entre $85 \%$ e $100 \%$ (figura 12), valores estabelecidos para ambientes com pouca perturbação (NESSIMIAN et al., 2008). Embora alguns trechos do SB-02 e o SB-03 sejam utilizados para fins de balneabilidade e tenham passado por processo de degradação devido à urbanização, suas margens apresentam zona ripária ainda definida e preservam algumas características naturais do leito. Segundo Bastos et al. (2004), a mata ciliar possui papel fundamental nos ecossistemas aquáticos, pois estão ligadas aos processos de óxido-redução e reciclagem de nutrientes dos ecótonos água-terra. No entanto, quando em abundância, ocorre o acúmulo de troncos e galhos dentro do leito, dificultando o fluxo de água e causando represamentos parciais.

O ponto SB-01 (56,9\%), SB-04 (70,1\%) e SB-05 (68,8\%) encontram- se com valores abaixo do padrão estipulado, logo foram classificados como ambientes com forte perturbação, por apresentarem margens descaracterizadas e modificadas, devido a retirada da vegetação. Dessa forma, o igarapé torna-se suscetível ao assoreamento dos leitos e intensa exposição solar, com consequente aumento da luminosidade e temperatura (BASTOS et al., 2004).

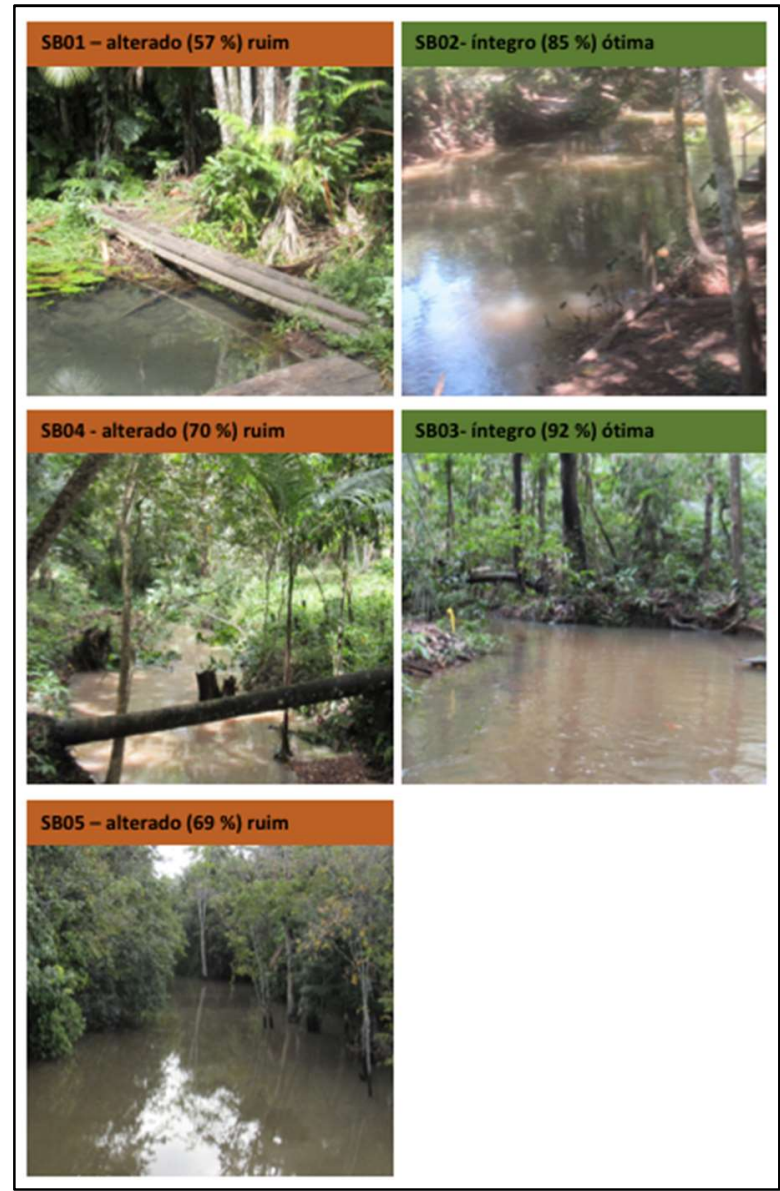

Figura 12: Índice de integridade do habitat para os cinco pontos amostrais, considerando preservados ou em condições ótimas somente aqueles com valores obtidos maiores ou igual a 0,85 ou $85 \%$.

A integridade do habitat resume bem o estado de conservação dos igarapés por incorporar variáveis de múltiplas escalas espaciais, aquáticas e terrestres (BLEICH et al., 2014), que juntas mantém e modelam estes ecossistemas complexo. Desse modo, as informações de caracterização da bacia e de seus afluentes 
aqui apresentados podem fomentar a elaboração de projetos para a recuperação da estrutura e funções iniciais desses ecossistemas, bem como a melhorar a gestão territorial na área da bacia.

\section{CONCLUSÕES}

A bacia hidrográfica do igarapé São Braz foi classificada com tendência circular e com área igual a $234.738 \mathrm{~km}^{2}$. As características hidrológicas e limnológicas estudadas apresentam variação espacial e temporal, mas sem a presença de um padrão. A estocasticidade observada pode ser decorrente da intensidade e origem dos processos promotores de degradação ambiental nas nascentes hidrográficas estudadas

O índice de integridade do habitat utilizado foi capaz de determinar o estado de degradação dos igarapés estudados na bacia hidrográfica do São Braz. Apenas duas nascentes, São Braz e Irurama, foram determinadas como íntegras. A área de estudo em questão mostrou o ponto SB-03 como ambientes íntegros com condições favoráveis para manutenção da vida aquática seguido do SB-02. No entanto, os demais pontos amostrados foram classificados como ambientes com forte perturbação, que podem ter sido consequência de atividades antrópicas como desmatamento, balneabilidade e moradia ao entorno dos seguimentos.

\section{REFERÊNCIAS}

ABISABER, B.. Metrópoles da Amazônia correm risco de crise hídrica por contaminação da água. São Paulo: LEB, 2015.

ARCOVA, F. C. S.; CICCO V. Qualidade da água de microbacia com diferentes usos do solo na região de Cunha, Estado de São Paulo. Scientia Forestalis, n.56, p.125-134, 1999.

BALLESTER, M. V. R.; VICTORIA, D. C.; KRUSCHE, A. V.; COBURN, R.; VICTORIA, R. L.; RICHEY, J. E.; LOGSDON, M. G.; MAYORGA E.; MATRICARDI E.. A remote sensing/GIS-based template to understand the biogeochemistry of the JiParaná river basin (western Amazônia). Remote Sensing of Environment, v.87, p.429-445, 2003.

BASTOS, P. L.; ABILHOA, V.. A utilização do índice de integridade biótica para avaliação da qualidade de água: um estudo de caso para os riachos urbanos da bacia hidrográfica do Rio Belém, Curitiba, Paraná. Revista Estudos de Biologia, Curitiba, v.26, n.55, p.33-44, 2004.

BLEICH, M. E.; MORTATI, A. F.; ANDRÉ, T.; PIEDADE, M. T. F. Riparian deforestation affects the structural dynamics of headwater streams in Southern Brazilian Amazonia. Tropical Conservation Science, v.7, n.4, p.657-676, 2014.

BONATO, F.; SANTOS, L. J. C.. Análise de Bacias Hidrográficas em Meio Urbano - Estudo de Caso: Bacia Hidrográfica do Ribeirão dos Padilhas - Curitiba/PR. Revista Eletrônica Multidisciplinar FACEAR, 2008.

BRASIL. Ministério da Saúde. Manual de controle da qualidade da água para técnicos que trabalham com ETAS. Brasília: MS, 2014.
CARDOSO, C. A.; DIAS, H. C. T.; MARTINS, S. V.; SOARES, C. P. B.. Caracterização hidroambiental da bacia hidrográfica do Rio Debossan. Nova Friburgo: 2005.

CARVALHO, D. F.; MELLO, J. P. L.; SILVA, L. D. B.. Hidrologia. Irrigação e Drenagem, Rio de Janeiro, v.117, 2007.

CHIOQUETA, J. E.. Diagnóstico Ambiental da Bacia Hidrográfica do Rio Pato Branco. Curitiba: UFPR, 2011.

ESPÍRITO-SANTO, H. M. V.; MAGNUSSON, W. E.; ZUANON, J.; MENDONÇA, F. P.; LANDEIRO, V. L.. Seasonal variation in the composition of fish assemblages in small Amazonian forest streams: evidence for predictable changes. Freshwater Biology, v.54, p.536-548, 2009.

GARCEZ, L. N.; ALAREZ, G. A.. Hidrologia. 2 ed. São Paulo: Edgard Blucher, 1988.

LIBÂNIO, M.. Fundamentos de qualidade de água e tratamento de água. 3 ed. Campinas: Átomos, 2010

LIMA, W. P.. Análise física da bacia hidrográfica. São Paulo: USP, 2017.

MACHADO, R. A. S.; LOBÃO, J. S. B.; VALE, R. M. C.; SOUZA, A. P. M. J.. Análise morfométrica de bacias hidrográficas como suporte à definição e à elaboração de indicadores para a gestão ambiental a partir do uso de biotecnologias. In: Simpósio Brasileiro de Sensoriamento Remoto (SBSR), 2011 Curitiba. Anais. Curitiba: INPE, 2011.

MCCLAIN, M. L.; ELSENBEER, H.. Terrestrial inputs to Amazon streams and internal biogeochemical processing. In: MCCLAIN, M. E., VICTORIA, R. L.; RICHE, J. E.. The Biogeochemistry of the Amazon Basin. New York: Oxford University Press, 2001. 
MENDONÇA, F. P.; MAGNUSSON, W. E.; ZUANON, J. Relationships Between Habitat Characteristics and Fish Assemblages in Small Streams of Central Amazonia. Copeia, v.4, p.750-763, 2005.

NEILL, C.; ELSENBEER, H.; KRUSCHE, A. V.; LEHMANN, J.; MARKEWITZ, D.; FIGUEIREDO, R. O.. Hydrological and biogeochemical processes in a changing Amazon: results from small watershed studies and the large-scale biosphereatmosphere experiment. Hydrological Processes, v.20, p.2467-2476, 2006

NESSIMIAN, J. L.; VENTICINQUE, E. M.; ZUANON, J.; MARCO JUNIOR, P.; GORDO, M.; FIDELIS, L.; BATISTA, J. D.; JUEN, L.. Land use, habitat integrity, and aquatic insect assemblages in Central Amazonian streams. Hydrobiologia, v.164, p.117131, 2008.
SCHUMM, S. A.. Evolution of drainage systems and slopes in badlands of Perth Amboy. Geological Society of America Bulletin, n.67, p.597-646, 1956.

SILVEIRA, A. L. L.. Ciclo hidrológico e bacia hidrográfica. In: TUCCI, C. E. M.. Hidrologia: ciência e aplicação. São Paulo: EDUSP, 2001.

TUCCI, C. E. M.. Águas urbanas. Estudos Avançados, v.22, n.63, 2008.

TUNDISI, G. J.; TUNDISI, T. M.. Limnologia. São Paulo: Oficina de textos, 2008.

VENTURA, R. M. G.. Caracterização ambiental e hidrológica da bacia do córrego Barbado em Cuiabá (MT). Dissertação (Mestrado em Engenharia de Edificações Ambientais) Universidade Federal de Mato Grosso, Cuiabá, 2011.

A CBPC - Companhia Brasileira de Produção Científica (CNPJ: 11.221.422/0001-03) detém os direitos materiais desta publicação. Os direitos referem-se à publicação do trabalho em qualquer parte do mundo, incluindo os direitos às renovações, expansões e disseminações da contribuição, bem como outros direitos subsidiários. Todos os trabalhos publicados eletronicamente poderão posteriormente ser publicados em coletâneas impressas sob coordenação da Sustenere Publishing, da Companhia Brasileira de Produção Científica e seus parceiros autorizados. Os (as) autores (as) preservam os direitos autorais, mas não têm permissão para a publicação da contribuição em outro meio, impresso ou digital, em português ou em tradução. 